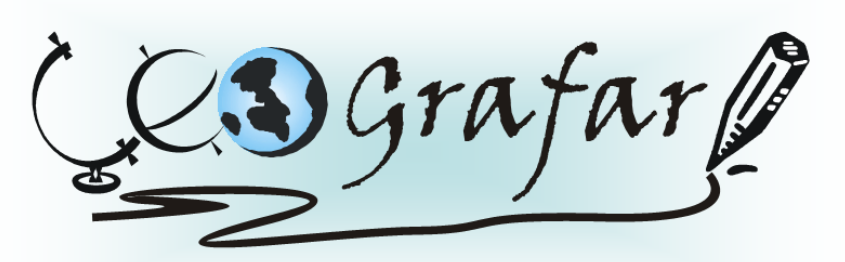

Revista Eletrônica do Programa de Pós-Graduação em Geografia - UFPR

\title{
IMPACTOS SÓCIO-AMBIENTAIS DO TURISMO EM ÁREAS LITORÂNEAS: UM ESTUDO DE PERCEPÇÃO AMBIENTAL NOS BALNEÁRIOS DE PRAIA DE LESTE, SANTA TERESINHA E IPANEMA - PARANÁ
}

\author{
NEUMAR BERGUERAND RIBEIRO DA COSTA ${ }^{1}$
}

\begin{abstract}
RESUMO
O presente trabalho objetivou realizar um estudo de percepção na visão dos moradores sobre os impactos sócio-ambientais ocasionados pela atividade turística nos balneários do litoral paranaense. Portanto, este visou detectar através da percepção ambiental, as possíveis transformações ocorridas bem como os meios para minimizar impactos negativos e conhecer as expectativas dos moradores quanto ao melhoramento local. Assim, a Percepção como orientação epistemológica calcada na subjetividade e na experiência vivida, veio melhor compreender a conduta e a reação dos indivíduos face à realidade sócioeconômica e ambiental do meio. Metodologicamente, o estudo compreendeu, além da bibliografia, a observação direta sobre fontes primárias como as anotações de campo e a pesquisa prática através da coleta de dados. Os principais resultados do estudo giraram em torno do turismo de férias concentrado nas temporadas e suas conseqüências. Desse modo, avaliações sobre percepção de impactos do turismo em áreas litorâneas vêm proporcionar um conjunto de bases reais para análise, interpretação e planejamento de espaços turistificados.
\end{abstract}

Palavras-chave: Impactos sócio-ambientais, percepção, turismo.

\footnotetext{
${ }^{1}$ Mestranda em Geografia pela Universidade Federal do Paraná; Área de concentração: Produção e Transformação do Espaço Urbano e Regional. E-mail: neuberg@ig.com.br
} 


\title{
SOCIAL AND ENVIRONMENTAL IMPACTS OF THE TOURISM IN COASTAL AREAS: A STUDY OF ENVIRONMENTAL PERCEPTION IN THE BEACH RESORTS OF PRAIA DE LESTE, SANTA TERESINHA E IPANEMA - PARANÁ
}

\begin{abstract}
The present work consider as objective, to carry through a study of perception in the vision of the inhabitants on the social and ambient impacts caused by the tourist activity in the some Beach health-resorts in Paraná. Such study, it aims at a similar survey to detect through the ambient perception, the possible occurred transformations as well as the identification of ways that can minimize the negative impacts and know the expectations of the inhabitants how much to the local improvement. For in such a way, it was adopted Perception as epistemological orientation for the study, based on the subjectivity and the lived, similar experience of better understanding the behavior and the reaction of the individuals front to the social and economic and ambient reality of the way. Methodologically, the study included, in addition to the literature, direct observation of primary sources and field notes and research practice through data collection. The main results of the study revolved around the holiday tourism season and focused on its consequences. Thereby, evaluations on perception of social and ambient impacts of the tourism in areas of the coast, being able of this form, to supply to subsidies the management programs, in the direction to provide a set of real bases analysis, interpretation and planning of the tourism spaces.
\end{abstract}

Key words: Social and ambient impacts, perception, tourism.

\section{INTRODUÇÃO}

$\mathrm{Na}$ atualidade, as interações entre o homem e o meio ambiente estão passando, cada vez mais, por crises provocadas pelo uso indiscriminado dos recursos da natureza. Como resultado, há uma grande sucessão de desequilíbrios e transformações do meio ambiente no panorama mundial.

Ressalta-se que esses ambientes naturais e construídos são considerados as bases físicas das mais variadas atividades humanas. No entanto, nas atividades sociais, comerciais, culturais e de lazer são tomadas medidas inadequadas de uso que podem alterá-los de forma prejudicial e irreversível. 
Nesse sentido, o turismo, considerado um fenômeno sociocultural característico da sociedade capitalista industrial e urbanizada, vem ultimamente despertando interesses em meios naturais e dessa forma abrangendo áreas ambientalmente frágeis ou de preservação. Assim, a atividade turística se encontra repleta de práticas que requerem, com urgência, mudanças de percepções, valores, atitudes e representações sociais, pois essas práticas alteram todo um conjunto de condições naturais e que refletem também em suas interações.

Em grande parte das áreas litorâneas do Brasil, o turismo impõe grande influência sobre a realidade sócio-ambiental, principalmente por suas incursões de natureza econômica. Essa atividade gera impactos positivos como empregos, renda e melhoria de infraestruturas urbanas, e também negativos como crescimento desordenado, desigualdades sociais e degradação do meio ambiente.

Desse modo, o trabalho aqui descrito foi realizado nos anos de 2006 e 2007 como um estudo de percepção ambiental através do ponto de vista dos moradores dos balneários de Praia de Leste, Santa Teresinha e Ipanema, tendo como problemática os impactos sócio-ambientais deixados pela atividade turística.

Para esta abordagem, foram aplicados os conceitos da chamada Geografia da Percepção, a fim de conhecer as suas incidências dentro da atividade turística. $E$, portanto, com relação a esta, o tema se estabeleceu na especificidade das atividades humanas relacionadas ao turismo.

Neste estudo, considerou-se como atividade turística aquela realizada pelo turista visitante nas altas temporadas de veraneio, sendo tipificada por Andrade (2002) como turismo de férias, que constitui, como um todo, a demanda mais significativa para a economia local.

Os locais escolhidos para a pesquisa encontram-se situados no Município de Pontal do Paraná, compreendendo os balneários de Praia de Leste e Ipanema ambos caracterizados por uma crescente área urbana, e Santa Teresinha, também denominado Cidade Balneária Atlântica - conhecido pelo turismo concentrado em época de carnaval, com maior freqüência de público jovem e agitada vida noturna.

Nesse aspecto, Praia de Leste, Santa Teresinha e Ipanema, quanto ao tipo de turismo e situação sócio-ambiental, possibilitaram uma análise bastante representativa por refletir um quadro semelhante ao dos demais balneários do município. E embora os locais descritos simplesmente sejam denominados de 
balneários, estes vêm experimentando um acelerado processo de urbanização ao longo das últimas décadas.

Além do citado, outro motivo de escolha da área sustentou-se no fato destes pertencerem a um município emancipado recentemente. Sendo que em época anterior eram vistos e considerados como balneários isolados e com pouca atenção por parte da administração municipal a que pertenciam, motivo pelo qual foi reivindicada a emancipação.

Portanto, o presente estudo teve como objetivo geral avaliar, através da percepção dos moradores de Praia de Leste, Santa Terezinha e Ipanema, os impactos gerados pelo turismo em seu ambiente de vivência (social), bem como as transformações trazidas por estes nestas áreas.

Do mesmo modo e para atingir tal objetivo, foram lançados os seguintes objetivos específicos:

a) Identificar, através da percepção dos moradores dos três balneários, os impactos sócio-ambientais causados pelos turistas a estas áreas (positivos e negativos);

b) Identificar, do ponto de vista sócio-econômico, os impactos positivos e negativos trazidos pelo turismo à localidade;

c) Detectar, considerando a percepção dos moradores, as possíveis transformações na paisagem em decorrência do turismo realizado;

d) Conhecer, a partir dos levantamentos de campo, as expectativas da população da área estudada, quanto à recuperação, acessibilidade e melhoria das políticas de desenvolvimento regional.

Partindo de tal proposta, trabalhos de percepção ambiental que têm como alvo principal os moradores locais tendem a uma maior eficiência face aos levantamentos puramente técnicos. Pois nestes últimos, nem sempre os resultados obtidos correspondem à realidade sócio-ambiental do morador em seu lugar de vivência.

O meio ambiente aqui considerado e de acordo com Silveira (2002), é constituído pelo ambiente natural (biológico e físico), pelo ambiente construído (a produção do espaço pelo homem) e pelo ambiente sócio-econômico, político e cultural (a sociedade). Inclui todas as relações entre a sociedade e os elementos físico-naturais que ocorrem no espaço geográfico, ou seja, considera a sua totalidade, natural e construída, sociocultural e tecnológica, política e econômica. 
Portanto, embora se tenha estudado os demais enfoques sócio-ambientais, no presente trabalho dedicou-se maior atenção à temática do meio ambiente, visto que, no panorama da atualidade este vem constituindo uma preocupação crescente e cada vez mais inquietante para as mais variadas esferas - dos governos em todos os níveis, de empresas privadas e também em escala individual. Além de que, podese enfatizar ainda que os estilos de vida urbanos modernos tendenciam uma demanda cada vez maior pela busca de lazer em áreas naturais e principalmente em regiões litorâneas.

\section{A GEOGRAFIA: PERCEPÇÃo AMBIENTAL, TURISMO, ORDENAMENTO DO TERRITÓRIO E IMPACTOS SÓCIO-AMBIENTAIS}

Em seu vasto campo de ação, a Geografia, para grande parte dos geógrafos, jamais deveria se limitar ao contexto das ciências físicas, submetendo então, seus estudos, à produção de uma "Geografia Humana", onde a análise do espaço se realizaria em função do homem e suas ações.

Segundo Moraes (2003) os princípios da Geografia Moderna foram apoiados nas ciências físico-naturais e nas ciências humanas, tornando assim a geografia, uma ciência interpretativa, ou seja, não se contenta apenas em descrever os fatos analisados ou o conjunto da paisagem, procura interpretá-los.

Moraes (2003) então finaliza que alguns autores definem a geografia como o estudo das relações entre o homem e o meio, ou, posto de outra forma, entre a sociedade e a natureza.

Assim, a especificidade estaria no fato de essa disciplina buscar explicar o relacionamento entre os dois domínios da realidade, onde seria, por excelência, uma disciplina de contato entre as ciências naturais e as humanas, ou sociais.

De acordo com Amorim Filho e Abreu (2002), desde o final do século XIX, a geografia passa a incluir cada vez mais os fatos humanos em suas pesquisas e reflexões (nascimento da Geografia Humana), conservando uma postura predominantemente naturalista e racionalista. A objetivação e o objetivismo são, assim, as categorias comumente - e muitas vezes automaticamente - empregadas pelos geógrafos para fazer a mediação entre o homem naturalista e racionalista e objetos, paisagens e, até mesmo, os outros homens. 
A partir dessa pluralidade de enfoques e segundo Mello (1990), uma nova abordagem para a geografia - a corrente humanística - surge nos anos 70 procurando interpretar a multiplicidade dos acontecimentos do mundo vivido e trabalhando, para tanto, com valores e sentimentos dos seres humanos. Esta tendência exprime o exato oposto das perspectivas positivistas que não pretendiam ou nem mesmo conseguiam explicar o mundo vivido, com suas leis e teorias mecanicistas, acabadas e abstratas.

Para o mesmo autor (1990), esta Geografia Humanística com bases filosóficas calcadas na Fenomenologia, a importância está na experiência vivida, no objetivo de interpretar o sentimento e o entendimento dos indivíduos relacionados com o espaço e o lugar, ou seja, o vivencial.

Segundo Amorim Filho (1987), a percepção, como nova abordagem dentro da ciência geográfica, veio a se consolidar na segunda metade do século $X X$, embora, ao longo dos tempos, já venha sendo estudada direta ou indiretamente por muitos pesquisadores. Tais estudos se utilizam de fontes teóricas desenvolvidas pela psicologia, e em particular, das teorias sobre comportamento, com rápida evolução na década de sessenta e principalmente na década de setenta.

No Brasil, de acordo com o mesmo autor (1987 e 2006), os estudos de Percepção ambiental surgem na década de setenta, iniciando-se a partir do primeiro trabalho de Lívia de Oliveira em 1977 para esta abordagem, e posteriormente, entre as décadas de 70 e 90, vindo a ser largamente aplicada nos estudos de Del Rio, Kohlsdorf, Bley, Machado e outros.

Logo, a geografia com ênfase na percepção ambiental e na espacialidade traduz uma necessidade em compreender o novo enfoque para as relações indivíduo-meio ambiente, com seus valores, significados e conflitos, em função de um espaço cada vez mais globalizado pela estandardização do consumo e dos modelos sócio-econômicos atuais.

\section{1 OS ESTUDOS DE PERCEPÇÃO AMBIENTAL E A ATIVIDADE TURÍSTICA}

Dentro da ciência geográfica e na atualidade, os estudos de percepção ambiental, como elucidado anteriormente, vêm cada vez mais adquirindo uma 
importância fundamental no sentido de possibilitar e melhorar a compreensão das inter-relações entre o homem e o meio ambiente.

Nestes estudos são evidenciados como as características ambientais do meio geográfico podem influenciar os indivíduos em conjunto com suas emoções e sentidos, fornecendo assim, elementos para mensurar e avaliar situações, e a partir daí, direcionar suas atividades e seu modo de vida.

Alguns autores destacam-se no tema, como Oliveira (1996, p. 3) que define a percepção sendo "um processo mental de interação do indivíduo com o meio ambiente que se dá através de mecanismos perceptivos propriamente ditos e, principalmente cognitivos".

De acordo com Tuan, citado por Oliveira (2000), os indivíduos, no decorrer de sua vivência, percebem, reagem e respondem diferentemente frente às ações do meio a que estão expostos, considerando assim, os fatores educativos, culturais, emotivos e sensitivos. As respostas ou manifestações são, portanto, resultados das percepções dos processos cognitivos, bem como os julgamentos e expectativas de cada indivíduo. Embora nem todas as manifestações psicológicas sejam evidentes, estas são constantes e vem afetar a forma de conduta, na maioria das vezes, de modo inconsciente.

Atualmente, a maioria dos autores é motivada por essa perspectiva, onde lidam com o conceito de percepção no sentido mais amplo possível, considerando um conjunto de fatores. Assim, os estudos de percepção reconhecem a idealização do espaço valorizando o posicionamento ideográfico dos indivíduos - o modo como estes realmente o percebem - sem qualquer forma de reflexão objetiva ou coletiva.

Para Tuan (1980, p. 14), "a percepção é uma atividade, um entender-se para o mundo". A partir daí, utiliza-se em um sentido mais amplo que a percepção abrangida pela inteligência entende, compreende e adquire conhecimento mediante o funcionamento dos sentidos. Assim, faz-se interligar o meio ambiente à percepção que o indivíduo tem do mesmo, pois a primeira questão que se coloca é de como o homem sente e percebe o mundo que o rodeia.

Nesse sentido, a percepção do ambiente geográfico produz efeitos positivos ou negativos sobre a paisagem e a atividade turística, que tem no meio natural o seu principal recurso. Portanto, a beleza ou a degradação das paisagens, o ambiente 
intocado ou poluído, tem grande importância no desenvolvimento da atividade, onde também é somada a influência dos valores e da cultura.

Segundo Rodrigues (2001), para a geografia moderna com vista também para o desenvolvimento econômico, o turismo, considerado um fenômeno social, tornouse cada vez mais um elemento de destaque, observando em suas incursões, uma grande capacidade do mesmo em desenvolver regiões e transformar espaços.

Assim, os estudos de percepção podem também permitir a esta geografia uma nova concepção - uma visão mais abrangente acerca do espaço geográfico, necessária para se compreender os mecanismos de funcionamento e produção deste, para então poder ser conhecido, explorado ou consumido adequadamente.

Neste contexto, Gade (1980) coloca a necessidade de entender o turismo em suas diferentes modalidades implicando compreender os interesses e motivações do consumidor, com definições que procuram explicar essas relações como atividade econômica e/ou como reflexos sociais, culturais, comportamentais e ambientais.

A mesma autora (1980) aborda a percepção com influência no comportamento do consumidor, colocando que a tomada de decisão em consumir se dá em função de vários fatores, entre eles, os psicológicos (vontade e emoção) e os sociológicos (tempo e renda), considerando que os valores pessoais determinarão o grau de importância para cada produto e para cada momento de consumo.

Pode-se dizer que o fenômeno do turismo constitui uma atividade multidisciplinar que possibilita uma interação entre o turista e o local receptor, sendo que ao turista proporciona atividades, conhecimentos e experiências decorrentes dessa interação, desencadeados por seus processos perceptivos e cognitivos.

Através do instrumental da percepção, turistas procuram vivenciar suas expectativas na realidade, agregando aos lugares os valores relacionados a seus sonhos e fantasias de consumo, quaisquer que seja o tipo de turismo. Por outro lado, moradores de locais turísticos vivenciam transformações em seu meio e muitas vezes em seu modo de vida, deixado pela atividade turística e suas incursões.

Assim, constitui-se para a geografia outro acréscimo da importância dos estudos de percepção, enfocando todo o potencial do ambiente e a valorização da paisagem como elementos essenciais para o conjunto da atividade turística.

\section{2 ORDENAMENTO DO ESPAÇO TURÍSTICO}


Atualmente a atividade turística tem se apresentado como um fenômeno crescente, cada vez mais difundido e diversificado, tendo como resultado uma grande segmentação mercadológica e com tendências hegemônicas globais.

A considerar o turismo também como um produto de consumo procurando atrair pessoas a explorar seus espaços, Rodrigues (2001, p. 27) salienta que este "introduz novos códigos culturais e propõe novos sistemas de símbolos baseados em imagens que substituem a realidade e conduzem a julgamentos segundo códigos impostos pela mídia". Isto faz compreender que a publicidade, através dos meios de comunicação e recursos visuais elaborados, difunde imagens de lugares paradisíacos, no intuito de venda e propagação desses produtos.

Para Silveira (2002), no atual contexto da economia globalizada atribui-se ao turismo um papel relevante na busca do desenvolvimento territorial. Governos nacionais, regionais e locais, administradores e gestores públicos, enfim, todos aqueles que formulam as chamadas políticas de desenvolvimento econômico, tanto nos países desenvolvidos quanto naqueles em desenvolvimento, passaram a ver o turismo como uma poderosa ferramenta para alavancar o desenvolvimento regional.

Porém, sem qualquer controle, a atividade turística pode causar inúmeras transformações, e, mediante uma atuação desordenada e mal planejada torna-se grande propiciadora de impactos provocando degradações ao meio ambiente.

Para tanto e estendendo-se em âmbito global, atualmente o turismo passou a ser regido segundo as premissas do desenvolvimento sustentável ${ }^{2}$, o qual é reconhecido e adotado pela comunidade internacional como objetivo comum para embasamento de todas as atividades.

Dessa forma, a Agenda 21 foi assumida como documento compromisso pelos países representados na Conferência ECO - 92 no Rio de Janeiro, como um acordo para tomada de decisões em prol do desenvolvimento sustentável. Neste, procurase uma união para o estabelecimento de políticas voltadas para o crescimento econômico das nações, buscando a minimização das desigualdades sociais aliados à conservação e uso sustentável dos recursos da natureza. Estas condições devem

\footnotetext{
${ }^{2}$ Amplamente utilizado nos dias atuais, o conceito de desenvolvimento sustentável foi consolidado em 1987 através do Relatório Brundtland "Our common future" (Nosso futuro Comum), pela Comissão Mundial sobre Meio Ambiente e Desenvolvimento, como "aquele que atende as necessidades do presente sem comprometer a possibilidade de as gerações futuras atenderem as suas próprias necessidades" (MINISTÉRIO DO MEIO AMBIENTE, Agenda 21, 2006).
} 
ser aplicadas a todos os setores da economia mundial (comércio, extrativismo, agricultura, indústria, infraestrutura básica, construção, educação, turismo, etc.) (MINISTÉRIO DO MEIO AMBIENTE, 2006).

Estas iniciativas perfazem um melhor direcionamento e maior integração entre os diversos setores que englobam a economia para um equilíbrio de condições.

Dentro dos mesmos objetivos, os planos de ordenamento dos territórios devem cumprir metas semelhantes, fazendo diferenciação e adequação de projetos e empreendimentos para cada área, explorando racionalmente os setores e procurando minimizar os impactos negativos.

Segundo Silveira (2001), o planejamento territorial é um instrumento que determina a organização do espaço por meio de diretrizes que apreendem o todo, as partes, a função e as relações desse espaço, mas que também deve ser flexível, de forma que possa se adaptar às circunstâncias imprevistas na sua elaboração.

Por esta razão, considerando a área estudada evidenciou-se a legislação de uso e ocupação do solo $^{3}$, elaborada pelo plano diretor do município para instituir parâmetros de ocupação com a finalidade de adequar formas de uso e preservar ao máximo as áreas naturais. E assim, visando o melhor aproveitamento do território envolvendo limitações e potencialidades.

Portanto, a elaboração de projetos voltados à análise territorial junto à legislação é imprescindível para a atividade turística, onde esta, com envolvimento da comunidade local beneficia-se pelo uso adequado dos recursos e estabelece a manutenção do potencial turístico. Sendo que ainda, a qualidade dos atrativos pode promover o turismo à captador de recursos econômicos e outros investimentos.

\section{3 TURISMO E IMPACTOS SÓCIO-AMBIENTAIS}

\footnotetext{
${ }^{3}$ Dispõe sobre o zoneamento, uso e ocupação do solo nas áreas urbanas do município e outras providências. Observa-se que para o litoral paranaense a legislação de uso e ocupação do solo tem seu amparo jurídico na Lei Federal №. 6513, de 20 de dezembro de 1977, dispondo sobre a criação de Áreas Especiais e de Locais de Interesse Turístico e sobre o inventário com finalidades turísticas dos bens de valor cultural e natural. Esta Lei cria, na verdade, os fundamentos e o conceito de área protegida do ponto de vista legal. Através do seu artigo primeiro, define como de interesse turístico os bens de valor histórico, artístico, arqueológico ou pré-histórico; as reservas e estações ecológicas; as áreas destinadas à proteção dos recursos naturais renováveis; as manifestações culturais ou etnológicas e os locais onde ocorram; as paisagens notáveis; as localidades e os acidentes naturais adequados ao repouso e à prática de atividades recreativas, desportivas ou de lazer; as fontes hidrominerais aproveitáveis; as localidades que apresentam condições climáticas especiais (GOVERNO DO PARANÁ E PREFEITURA MUNICIPAL DE PONTAL DO PARANÁ, 2004).
} 
Embora o turismo seja visto como um fenômeno de alta complexidade mediante as condições ambientais do planeta, este é considerado um dos mais importantes vetores de desenvolvimento econômico mundial. Este setor passou a se tornar um dos principais alvos de investimentos, vislumbrando em determinadas situações e até em curto prazo, excelentes possibilidades de retorno financeiro.

Com base em Rodrigues (2001), o turismo já representa um dos produtos mais comercializados internacionalmente, apenas colocando-se atrás do petróleo e da indústria de armamentos. E, portanto, transformando-se numa das atividades econômicas mais importantes do mundo contemporâneo, recebendo cada vez mais atenção e seriedade no seu tratamento científico e técnico.

Globalmente identificada como "indústria sem chaminés", a atividade turística nas últimas décadas fomenta grandes empreendimentos buscando expandir e diversificar suas incursões, onde esta se apropria dos espaços transformando-os em objetos de consumo e muitas vezes provocando transformações sociais.

Com esta evolução, muitos são os exemplos de entraves e controvérsias gerados pela atividade nos dias atuais, a saber, por terem ocorrido sem qualquer forma de planejamento ou estudos preliminares, sendo:

\footnotetext{
"o turismo é considerado uma indústria e, assim como os demais setores da economia moderna, depende da apropriação e exploração da natureza e das sociedades locais. Os exemplos de degradação ambiental e sociocultural decorrentes do turismo são abundantes, assim como o são para a agropecuária ou outros setores da indústria: a utilização não sustentável até o esgotamento de suas fontes de matérias-primas e transferência para outros lugares de exploração" (MENDONÇA, 2001, p. 19).
}

Nas áreas urbanas das regiões litorâneas com elevada concentração turística em temporadas de veraneio torna-se necessário avaliar as condições sócioambientais para identificação dos impactos negativos podendo-se observar:

As localidades turísticas têm dificuldades em solucionar os problemas de saneamento básico, pois a demanda sobre estes serviços é multiplicada, às vezes, por cem, em épocas de temporada e fins de semana prolongados. Nesses períodos, os efluentes domésticos chegam a atingir níveis muito superiores à capacidade de saturação: os despejos de fossas e esgotos acabam contaminando as praias, comprometendo a balneabilidade de suas águas. É também difícil organizar a coleta de lixo, e muitas vezes é impossível estabelecer um local apropriado para o seu despejo que, ou fica disperso por várias áreas sem um tratamento adequado, ou a municipalidade deve negociar a sua deposição em algum município vizinho. São todas as soluções de curto prazo que prejudicam o potencial futuro para o desenvolvimento turístico (MENDONÇA, 2001, p. 22). 
A gravidade das situações descritas pressupõe fazer do turismo uma atividade mais ecológica e socialmente responsável. Para tanto, atualmente são adotados modelos de sustentabilidade como estratégia ideal para a integração entre o turismo, o desenvolvimento econômico e a preservação do meio ambiente.

Salienta-se que o conceito de sustentabilidade considerado neste estudo é amplo e fundamentado em determinados princípios segundo Sachs (1993, p. 37):

a) Sustentabilidade Ecológica - Entendida como a proteção da natureza e da diversidade biológica; portanto, o desenvolvimento turístico de respeitar a "capacidade de suporte" dos ecossistemas, limitar o consumo dos recursos naturais, e provocar o mínimo de danos aos sistemas de sustentação da vida;

b) Sustentabilidade Social - Fundamentada no estabelecimento de um processo de desenvolvimento que conduza a um padrão estável de crescimento, com uma distribuição mais eqüitativa de renda, redução das atuais diferenças sociais e garantia dos direitos de cidadania;

c) Sustentabilidade Cultural - Implica a necessidade de se buscar soluções de âmbito local, utilizando-se as potencialidades das culturas específicas, considerando a identidade cultural e o modo de vida local, assim como a participação da população local nos processos decisórios e na formulação e gestão de programas e planos de desenvolvimento turístico;

d) Sustentabilidade Econômica - Aquela que assegura o crescimento econômico para as gerações atuais e, ao mesmo tempo, o manejo responsável dos recursos naturais, que deverão satisfazer as necessidades das gerações futuras;

e) Sustentabilidade Espacial - Baseia-se na distribuição geográfica mais equilibrada dos assentamentos turísticos para evitar a superconcentração de pessoas, de equipamentos e de infraestrutura turística e, consequentemente diminuir a destruição de ecossistemas frágeis e a deterioração da qualidade da experiência do turista.

Estes princípios procuram direcionar o turismo sustentável encontrando-se amplamente difundidos e discutidos no âmbito das economias e centrados em políticas de planejamento territorial. A saber, consiste em um plano de ações descentralizadas beneficiando o território como um todo, e como já mencionado, considerando a capacidade de uso e suporte para seu zoneamento dentro de uma gestão democrática e participativa.

Porém, tais condições muitas vezes são controversas, como verificadas em pesquisas territoriais, inclusive estudos de percepção, onde 0 descaso da administração pública em relação à capacidade de carga ${ }^{4}$ do espaço local reflete de forma altamente negativa nos aspectos físico-naturais, biológicos e sociais.

\footnotetext{
${ }^{4}$ Este conceito possui quatro pilares essenciais que visam garantir a sustentabilidade da atividade turística: a) Capacidade de carga Ecológica/Ambiental: Define-se como o número máximo de visitantes que um lugar pode receber e, se superado, não poderá assegurar um desenvolvimento compatível com os recursos naturais; b) Capacidade de carga Social: Faz referência ao nível máximo
} 
Assim, pressupõe-se a necessidade em desenvolver um planejamento estratégico que integre todos os aspectos envolvidos, a fim de tornar o turismo realmente viável na totalidade das suas incursões.

Para Silveira (1997), no entanto, cabe discutir e propor formas concretas de se promover um turismo ambientalmente sustentável, economicamente viável e socialmente justo, e, como suporte, a dinâmica local e o planejamento participativo.

Desse modo, o planejamento integrado do turismo deve trabalhar todas as dimensões - territorial, social, econômica e ambiental - relacionando-as entre si da forma mais abrangente e fazendo repensar seus espaços.

Como descrito e observado por esta pesquisa, o contexto que engloba turismo, potenciais paisagísticos e território deve ser visualizado e entendido de modo a promover um desenvolvimento econômico e social satisfatórios aliando diferentes setores num compromisso conjunto em preservar o patrimônio ambiental numa relação harmônica e não predatória.

\section{METODOLOGIA}

Metodologicamente o estudo firmou-se como uma pesquisa exploratória, básica e de campo, com observação direta sobre fontes primárias.

$\mathrm{Na}$ estruturação do trabalho, quanto aos meios de investigação, o estudo compreendeu além da bibliografia, as anotações de campo e a pesquisa prática entrevista para aplicação do questionário como instrumento mais utilizado nas ciências do comportamento e percepção.

O questionário foi elaborado de forma que as perguntas abertas pudessem levar o entrevistado à maior objetividade para com a situação real vivenciada.

A técnica utilizada para a coleta dos dados - a Amostragem Randômica Estratificada segundo Raupp e Reichle (2003) consiste em separar os elementos da população útil em grupos mutuamente exclusivos, sendo tiradas amostras de cada estrato. A principal finalidade desse processo de seleção de amostras é garantir que

de atividade turística que, se superado, produzirá uma mudança negativa na população local; c) Capacidade de carga do Turista: Esta é entendida como o nível máximo que garante a satisfação do turista; d) Capacidade de carga Econômica: Esta se refere ao nível de atividade econômica compatível com o equilíbrio entre os benefícios econômicos que irá proporcionar o turismo e os impactos negativos que a atividade turística gera sobre as economias locais (manutenção das estruturas, desigualdades, inflação, etc.) (OMT, 2001, p. 248). 
cada estrato seja representado por uma amostra de tamanho adequado, ou seja, na mesma proporção da população. Desse modo, o erro de amostragem é minimizado.

Esse tipo de amostra possibilitou registrar o reflexo das percepções dos moradores nos locais designados - a área de maior concentração turística em cada balneário visando um potencial em avaliar a realidade percebida no tempo e local.

Para este critério de amostragem, na proporção das populações residentes em cada balneário foram aplicados 80 questionários com perguntas objetivas e abertas sendo 35 para Praia de Leste, 15 para Santa Teresinha e 30 para Ipanema.

As entrevistas foram realizadas com larga distância temporal da época de maior freqüência turística (veraneio), com o intuito de que as percepções dos moradores proporcionassem respostas com dados mais relevantes e significativos, sem a influência direta desta freqüência.

Assim, os locais de entrevista constituíram os pontos mais centrais de cada balneário, com maior incidência turística e concentração de moradores.

Para efeito de análise, na estruturação da pesquisa foram consideradas variáveis de grande importância para estudos de percepção como local de moradia, idade, gênero (sexo), grau de escolaridade e ocupação principal.

$\mathrm{E}$, portanto, podendo ser representado pelo esquema a seguir:

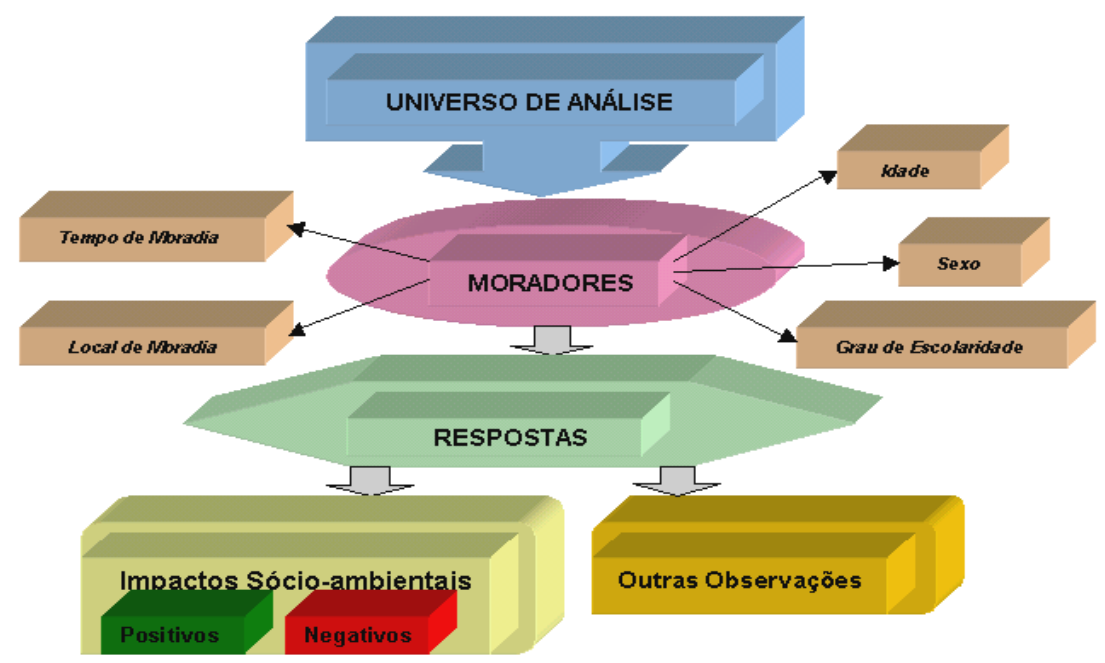

FIGURA 1 - A PESQUISA - ESTRUTURA GERAL

FONTE: A autora (2006) 
$\mathrm{Na}$ coleta dos dados, as respostas sendo uma ou mais fornecidas pelos entrevistados foram colocadas sob a forma de alternativas sucintas.

Os resultados obtidos foram analisados em conjunto para que pudessem ser destacadas observações e formuladas conclusões acerca da problemática em questão, com interpretação dos resultados e colocação das considerações finais.

Quanto à metodologia utilizada na pesquisa considerando os procedimentos e de acordo com Cruz e Ribeiro (2004), a abordagem indutiva pôde proporcionar observações espontâneas para efeito de análise e conclusão, relacionando o embasamento teórico à realidade observada.

Os dados fornecidos por órgãos federais, estaduais e municipais viabilizaram a consecução dos objetivos da pesquisa, onde, somando-se às informações obtidas (resultados dos questionários e anotações de campo) possibilitou-se um conhecimento maior direcionado à área de estudo - tanto para compreensão de suas interações sócio-ambientais quanto para entendimento de suas dinâmicas.

\section{CARACTERÍSticas GERAIS do Litoral PARANAENSE E ÁREA DE ESTUDO}

O estado do Paraná, segundo Angulo (1992) possui uma faixa litorânea (orla) pouco extensa - do sopé da serra até o oceano - com aproximadamente $90 \mathrm{~km}$ de comprimento e uma largura máxima em torno de 55 metros na região de Paranaguá.

A planície litorânea está profundamente recortada pelos complexos estuarinos das baías de Paranaguá, Laranjeiras, Pinheiros e Guaratuba, resultando em numerosas ilhas, algumas de grande extensão, como as ilhas das Peças, do Mel, Rasa, da Cotinga e Rasa da Cotinga. A planície tem em geral uma altura inferior a 20 metros acima do nível do mar, aumentando da costa para o continente, alcançando as maiores altitudes no sopé da serra (BIGARELLA, 1946).

A geologia costeira no litoral do Paraná é dominada por dois grandes compartimentos naturais, que são a planície costeira e a região montanhosa. A denominada Serra do Mar, região montanhosa, é composta pelos terrenos mais antigos, representados por migmatitos indiferenciados, granitos de anatexia, gnaisses, micaxistos indiferenciados e granitos alcalinos, pertencentes ao período Pré-Cambriano Superior (BIGARELLA, 1946). 
$\mathrm{Na}$ orla predominam os sedimentos arenosos marinhos, compreendendo areias quartzosas, aluviões, coluviões e sedimentos de baía. Portanto, a morfologia da planície litorânea se classifica em:

a) Sedimentação marinha - praias e restingas;

b) Sedimentação intermediária - manguezais, areia e bancos de lodo;

C) Sedimentação terrígena - aluviões terrestres e dunas eólicas (BIGARELLA, 1946).

Ressalta-se que no litoral paranaense, a despeito de sua pouca extensão e de acordo com a vegetação e a geomorfologia encontra-se uma grande variedade de ecossistemas, dos ambientes marinhos até os refúgios vegetacionais de altitude, podendo-se reconhecer diferentes unidades ambientais naturais sendo estas as serras, planaltos dissecados, restingas, mangues, marismas e outros (BIGARELLA, 1978; MAACK, 1981).

O clima, segundo a classificação de Köppen, é Subtropical úmido mesotérmico (Cfa), com verão quente, mês mais frio inferior a $18^{\circ} \mathrm{C}$, sem estação seca definida, com temperatura média anual estimada em torno de $22^{\circ} \mathrm{C}$ e precipitação média anual de 2000 mm (IPARDES, 2005).

Quanto ao quadro geral de preservação, segundo Angulo e Souza (1998), o ambiente natural do litoral paranaense encontra-se relativamente menos impactado do que no restante do estado, especialmente nos municípios de Guaraqueçaba e Guaratuba e nas áreas de serra em geral, pois esta região foi mantida à margem dos modelos de desenvolvimento adotados pelo Paraná ao longo das últimas décadas, predominantemente agrícolas ou agroindustriais. Por outro lado, nunca houve iniciativas em desenvolver a região por levar em consideração suas especificidades sociais e ambientais. O desenvolvimento do turismo na orla sul não é exceção, padecendo da problemática típica da urbanização costeira desordenada.

O município de Pontal do Paraná, o qual comporta as áreas de estudo, está situado a 119,50 km de distância da capital do estado, possui área total de 202.159 $\mathrm{km}^{2}$, população estimada em 18.848 habitantes, densidade demográfica de aproximadamente 93,23 habitantes $/ \mathrm{km}^{2}$, população rural de 174 habitantes e grau de urbanização de 98,79\%. Limita-se ao Sul, com o município de Matinhos; a Oeste, com o município de Paranaguá; ao Norte, com a baía de Paranaguá e a Leste com o 
Oceano Atlântico. Os acessos para as áreas do município são as estradas BR 277, BR 376, PR 407 e PR 412 (IPARDES, 2006).

Segundo a DIMUTUR - Diretoria Municipal de Turismo da Secretaria da Cultura, Esportes e Turismo de Pontal do Paraná (2006), as principais atividades econômicas do município são o turismo, o comércio, a pesca e o artesanato, sendo que este último encontra-se incluído no segmento turístico, bem como o setor comercial de representações - as imobiliárias. Pontal do Paraná caracteriza-se também por preservar a pesca artesanal, comportar o Centro de Estudos do Mar da Universidade Federal do Paraná e o porto de embarque para a llha do Mel.

De acordo com o Plano Diretor de Desenvolvimento Integrado elaborado pelo Governo do Paraná e Prefeitura Municipal de Pontal do Paraná (2004), o município foi recentemente instituído, sua história política iniciou-se por volta de 1983, quando surgiram as primeiras manifestações para a criação de um novo município compreendido entre os balneários de Pontal do Sul e Monções.

A partir de então, o seu surgimento deveu-se a uma grande manifestação popular para reivindicação e, portanto, para a sua emancipação política, em 20 de dezembro de 1995, e com implantação em 01 de janeiro de 1997 pela Lei Estadual n.. 11.252, desmembrando-se de Paranaguá.

Pontal do Paraná caracteriza-se como Área Especial de Interesse Turístico, condição definida pela Lei Estadual n. .9 12243/98. Conforme especificado na legislação, o município apresenta diversos aspectos que comprovam sua relevância no panorama turístico estadual produzindo fluxo populacional intenso no período de veraneio.

Dentre as áreas de relevância destacam-se as ocupações humanas da Colônia do Maciel, Colônia Pereira e Aldeia Indígena com traços culturais peculiares; a Estrada do Guaraguaçu e a Estrada Velha de Shangrilá, ambos os percursos passíveis de unificação e que formam uma trilha turística pela Floresta Atlântica; e as áreas da União, que permitem ao município a criação de locais de lazer sem que seja necessária uma desapropriação. Outro aspecto relevante são os sambaquis $\mathrm{A} e$ B do Guaraguaçu, que constituem os bens tombados municipais.

Contudo, o município ainda enfrenta problemas quanto às formas de uso e ocupação do solo, principalmente relacionados às ocupações irregulares que se distribuem sobre o ecossistema natural contrariando suas bases legais, embora 
possua uma legislação de zoneamento, uso e ocupação do solo elaborada em âmbito estadual. Há também outras deficiências, como um sistema viário desconexo que não atende à demanda de tráfego, escassez de infraestruturas e outros.

Como consta no Plano Diretor de Desenvolvimento Integrado - Governo do Paraná e Prefeitura Municipal de Pontal do Paraná (2004), para ordenamento do território, a legislação referente ao uso e ocupação do solo no município se divide mediante as seguintes disposições: Áreas Especiais de Interesse Turístico, Parcelamento do Solo, Zoneamento de Uso e Ocupação do Solo, Gestão Democrática do Uso do Solo e Macrozoneamento da Região do Litoral.

Entre estas, destaca-se o Zoneamento de Uso e Ocupação do Solo por especificar e definir as condições para o aproveitamento de áreas e locais considerados de interesse turístico, como um marco no processo de uso e ocupação do solo no litoral paranaense. O artigo oitavo do Decreto Estadual 2722 de 14 de março de 1984 estabeleceu este zoneamento para as áreas urbanas dos municípios de Matinhos, Guaratuba e balneários do município de Paranaguá (hoje Pontal do Paraná). Este, em verdade, institui parâmetros de ocupação, pois não estabelece usos para as zonas criadas.

Neste zoneamento foram criadas: as ZRs - Zonas Residenciais, para as quais são estabelecidas todas as especificações técnicas para as edificações; as ZEUs Zonas de Expansão Urbana; as ZAs - Zonas Agrícolas; e as ZPAs - Zonas de Proteção Ambiental, onde as especificações de uso são estabelecidas pelo órgão estadual competente de forma a preservar ao máximo as condições das áreas naturais. E assim representadas pelo Zoneamento Decreto Estadual 2722/84:

FIGURA 2 - ZONEAMENTO DECR. ESTADUAL 2722/84 - PONTAL DO PARANÁ 


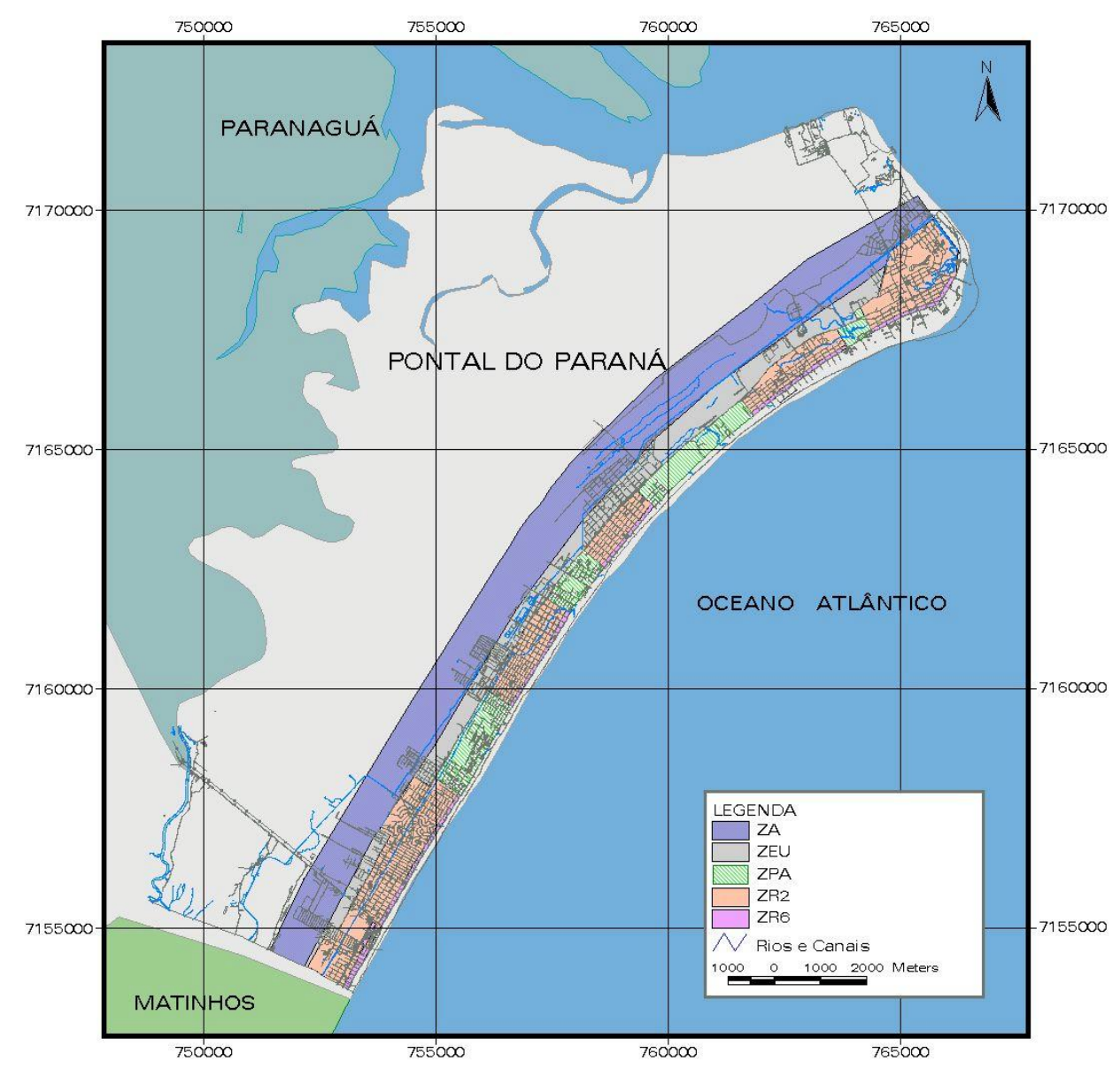

FONTE: COLIT (2003)

O município de Pontal do Paraná apresenta uma dinâmica populacional com duas categorias principais definidas por tratar-se de local turístico: população residente, também denominada como moradores locais; e população flutuante, formada por aqueles que exploram seus potenciais turísticos.

Como município de caráter turístico, em época de veraneio Pontal do Paraná recebe cerca de 450000 veranistas, segundo estimativas feitas pela Polícia Rodoviária sobre o número de veículos nas rodovias de acesso aos balneários, sendo que este número tem sofrido redução nos últimos anos. Essa configuração provoca mudanças significativas tanto no que se relaciona a infraestrutura urbana quanto aos fatores que influenciam no desenvolvimento econômico do município.

Pontal do Paraná possui o maior fluxo turístico de todo litoral do estado, segundo pesquisa realizada em 2003. O município recebe 33\% dos turistas que vêm ao litoral, seguido por Matinhos com 21\%, Paranaguá com 15\%, Guaratuba com $12 \%$, Morretes com $8 \%$, Antonina e llha do Mel com $5 \%$ e Guaraqueçaba com $1 \%$ 
(GOVERNO DO PARANÁ E PREFEITURA MUNICIPAL DE PONTAL DO PARANÁ. 2004).

O perfil de turistas de Pontal do Paraná, em geral caracteriza-se por uma população flutuante de procedência principalmente de Curitiba, seguido por outras regiões do Paraná, Região Metropolitana de Curitiba, outros estados e um pequeno fluxo constituído por turistas vindos de outros países.

De acordo com a DIMUTUR (2006) entre os diversos balneários de Pontal do Paraná destacam-se Ipanema e Praia de Leste pela maior população e seu aumento significativo nas altas temporadas de veraneio. Os outros atrativos turísticos são:

a) As baías e enseadas: como a Baía de Paranaguá, margeada pela Serra do Mar e com manguezais, dispõe de terminal de embarque (com barcos e similares) e a visitação é livre a qualquer época do ano;

b) Os mangues: constituem ecossistemas de fundamental importância dentro do estuário, atuam como berçário para várias espécies de animais e plantas que vivem na baía e em toda a zona costeira adjacente;

c) As restingas: são ecossistemas de transição entre as dunas e a Mata Atlântica, apresentam pequenas lagoas nos baixios entre os cordões arenosos, são compostas de vegetação de pequeno porte, mas com grande diversidade biológica. Compreendem a uma faixa de solo paralela à praia e protegida pelo Parque Natural Municipal do Perequê;

d) As ilhas: as Ilhas dos Currais e da Galheta são ambas de formação rochosa, sendo que a primeira e mais importante é composta por três pequenas ilhas com águas limpas e consideradas ideais para pesca e mergulho. Estas, atualmente, se encontram sob os cuidados do Centro de Estudos do Mar (UFPR), e, portanto, sua visitação é controlada.

Atualmente, a DIMUTUR participa de programas e outras ações onde, segundo esta, visa beneficiar e regulamentar o turismo como principal segmento da economia do município. Para os próximos períodos, conforme a mesma diretoria, planeja-se a organização e o controle efetivo da atividade turística nas altas temporadas possibilitando maior suporte para essa demanda e com a finalidade de impulsionar o desenvolvimento local. 


\section{A PESQUISA: DADOS COLETADOS, RESULTADOS E ANÁLISES.}

Embora Lima e Negrelle (1998) afirmem que a atividade turística no litoral paranaense pouco contribua para o seu desenvolvimento econômico, esta, porém, através do estudo de percepção direcionado ao público residente nos três balneários apresentou-se social e economicamente motivadora conforme a localidade.

Neste estudo, para Praia de Leste, Santa Teresinha e Ipanema, a análise dos resultados obtidos através da percepção ambiental dos moradores acerca dos impactos sócio-ambientais do turismo, constatou, além de alguns benefícios, a incidência tanto de problemas comuns quanto específicos, revelando suas principais causas e possíveis formas de solução.

Para efeito de análise observou-se no perfil dos moradores entrevistados, que em média, nos três balneários a maioria dos residentes havia ultrapassado dez anos de moradia no local. Entre estes, em Praia de Leste constava o maior número de moradores antigos e com maior faixa etária, alguns inclusive, se instalaram no balneário desde sua formação e povoamento.

Estes balneários apesar de possuírem grande semelhança em seu ambiente físico, apresentaram também algumas características sócio-ambientais particulares.

Todavia, através da percepção, o estudo visou ressaltar os impactos mais relevantes e seus reflexos imprimidos pelo turismo a estes locais, sendo diretamente mais e melhores sentidos pela população durante as temporadas de veraneio.

Observou-se que em dois dos balneários pesquisados - Praia de Leste e Ipanema - o turismo é visto como fonte de crescimento econômico (empregos e renda), urbano (infraestruturas) e populacional. No entanto, em Santa Teresinha (Cidade Balneária Atlântica), a atividade turística não é considerada, salvo em período específico de alta temporada - o carnaval.

Nos balneários em que o turismo é visto como gerador de empregos, renda e crescimento urbano, atribui-se também a este como impulsionador por oferecer suporte e desenvolver as demais atividades econômicas do município. E a atração para investimentos imobiliários tem proporcionado uma estrutura cada vez mais ampla para o comércio local e a diversificação da oferta de bens e serviços. 
Em geral, nestes balneários onde anteriormente empregos e renda eram vinculados apenas ao turismo de férias, atualmente são favorecidos por um quadro de urbanização crescente e motivados pelo desenvolvimento das infraestruturas e suas demandas. Contudo, comerciantes e até moradores com empregos formais ressaltaram diversificar suas atividades em função das temporadas de turismo.

Porém, evidencia-se que os problemas comuns aos três balneários destacamse por serem os mais essenciais, e, portanto, constantemente percebidos e vivenciados pelos moradores mesmo que fora das temporadas.

Através dos dados coletados a partir da pesquisa de percepção configurou-se o gráfico a seguir, que relaciona a satisfação dos moradores quanto às condições essenciais nos balneários com valores médios atribuídos em uma escala de 1 a 10:

\section{FIGURA 3 - SATISFAÇÃO DOS MORADORES - VALORES MÉDIOS ATRIBUÍDOS}

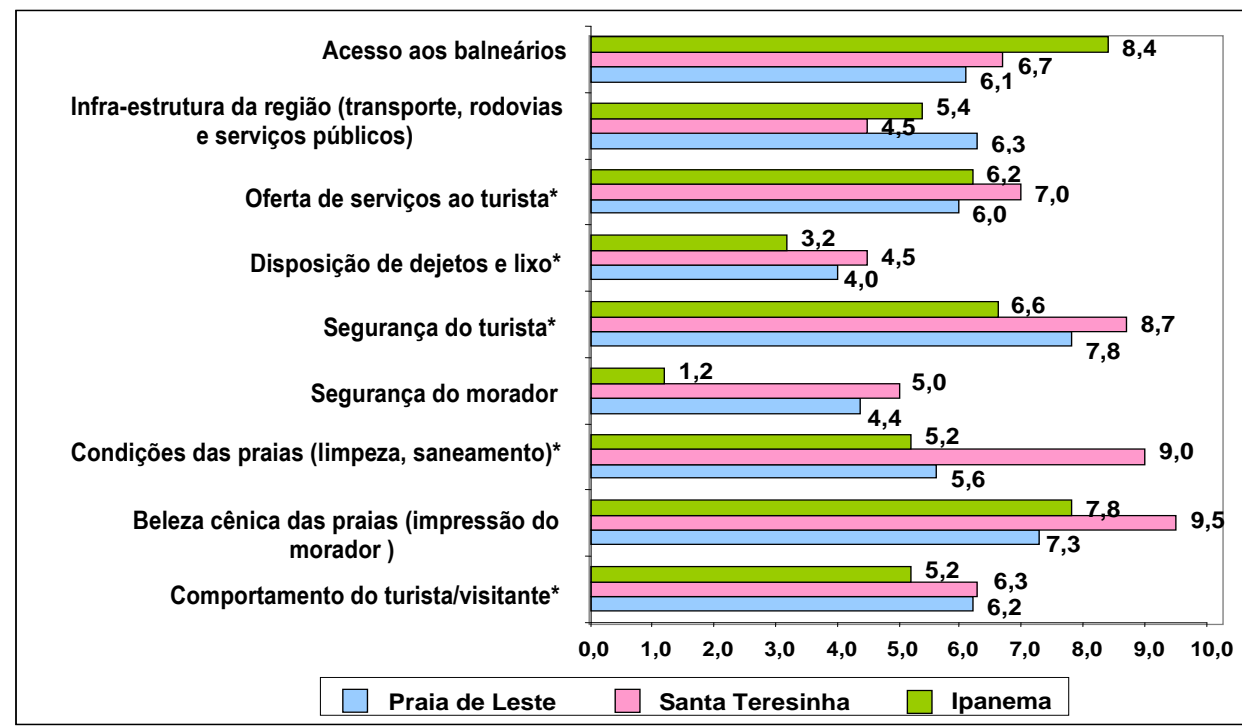

NOTA: * Itens de referência às temporadas de veraneio.

FONTE: A autora (setembro/2006).

Como representado no gráfico, em relação ao turismo das temporadas, os moradores lamentaram a precária educação e a indiferença do turista para com a manutenção da limpeza e conservação local. Estes comentaram, inclusive, que campanhas nesse sentido já foram realizadas, porém sem efeito. Mas acrescentaram que grande parte dos problemas poderiam ser amenizados se houvesse suporte estrutural adequado (sanitários e lixeiras com sinalizações ao longo da orla), onde há maior circulação de turistas. 
No gráfico destaca-se também outro problema comum e com o menor grau de satisfação - a insegurança dos moradores - considerada gravíssima para os balneários e resultando em grande preocupação por sua alta incidência fora das temporadas. Pois a precariedade da segurança local intranqüiliza moradores e principalmente a população flutuante composta de proprietários não residentes (veranistas e freqüentadores de finais de semana).

Segundo os moradores, a principal causa destes problemas reside no turismo concentrado e desordenado que se instala nos balneários por ocasião das temporadas de veraneio. Pois este turismo, além de desencadear transtornos de natureza ambiental como praias impróprias para recreação e excessivos acúmulos de lixo e dejetos, produz também transtornos urbanos como poluição sonora e congestionamento de veículos e pessoas.

Tais transtornos afetam inclusive àqueles que se beneficiam da própria atividade: "Além da insegurança e do descaso do turista para com a limpeza, o congestionamento faz o trabalho muito 'estressante' na temporada" (comerciante, 43 anos, Ipanema). Embora ainda haja os mais tolerantes: "É férias e temporada de praia é para se divertir" (comerciante, 65 anos, Praia de Leste); "É o período em que a 'moçada' se extravasa" (farmacêutico, 44 anos, Praia de Leste).

Quanto às demais infraestruturas, segundo os moradores, o aspecto positivo do turismo está associado principalmente à melhoria das rodovias e ampliação das vias de acesso. Daí o aumento do fluxo turístico requerendo maiores providências para suporte visando a manutenção da atividade.

Com relação a esse aspecto, algumas respostas constantes da pesquisa tiveram acréscimo de expressões como "o meu emprego se deve ao turismo" (zelador de condomínio, 33 anos, Santa Teresinha) e "se não houvesse o turismo, o lugar não cresceria" (comerciante, 39 anos, Ipanema).

Concluindo as análises e referente às situações mencionadas, um exemplo de impacto positivo e negativo que melhor caracteriza o turismo descrito pode ser facilmente observado no balneário de Ipanema conforme as seguintes ilustrações:

FIGURA 4 - IMPACTO POSITIVO 


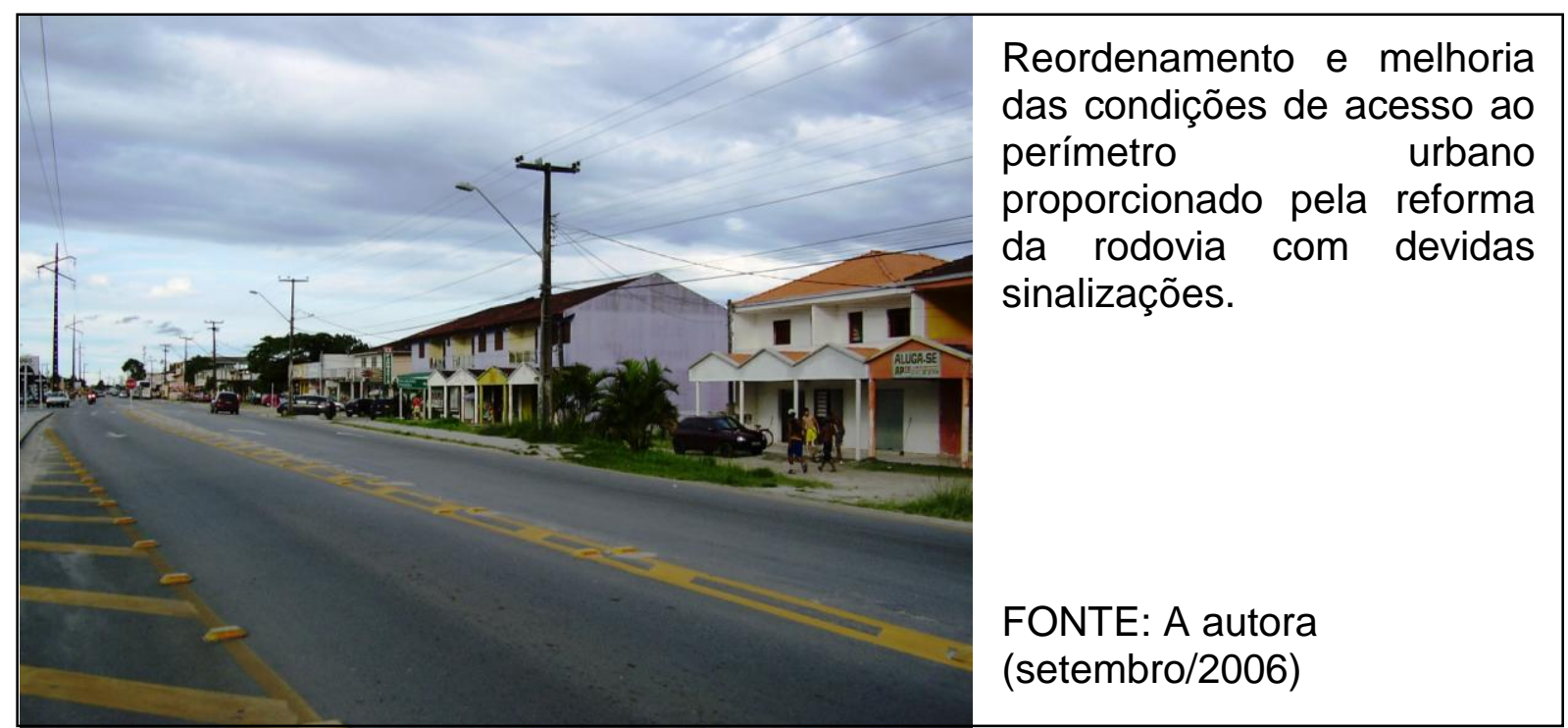

FIGURA 5 - IMPACTO NEGATIVO

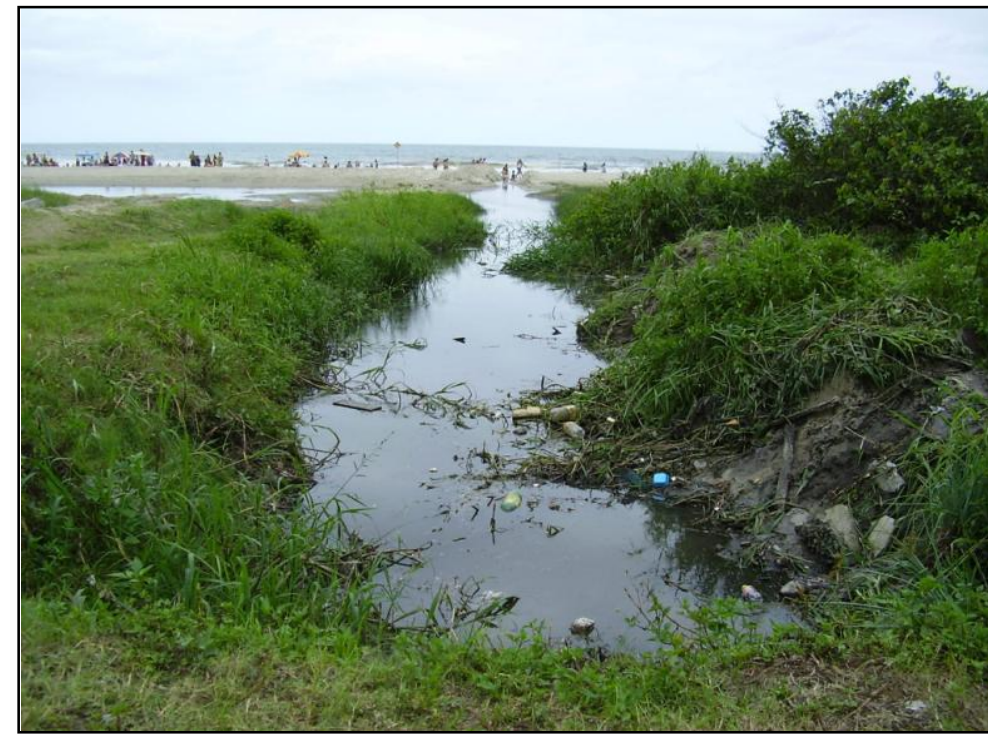

Aumento da deposição e concentração de lixo e dejetos, inclusive muito próximos às áreas de recreação (praia).

FONTE: A autora

(setembro/2006)

\section{A PERCEPÇÃO: AS CONSTATAÇÕES PARA A BUSCA DAS CONDIÇÕES SATISFATÓRIAS E AS CONSIDERAÇÕES FINAIS}

Através do estudo realizado, a aplicação desta vertente epistemológica da geografia - a percepção - como instrumento subjetivo de pesquisa que engloba raciocínio, sentimentos e valores, proporcionou detectar, qualitativamente, todo um quadro de condições locais para exposição tanto de problemáticas quanto de potencialidades. 
Atualmente, a grande incidência dos impasses de natureza sócio-ambiental constitui barreira para o desenvolvimento sustentável das sociedades e futuras gerações. Desse modo, esforça-se em implantar políticas para regulamentar as atividades humanas em prol da manutenção dos recursos naturais.

Porém, muitos planos de desenvolvimento dentro de modelos chamados "sustentáveis" apresentam-se fortemente direcionados a interesses econômicos. Estes, muitas vezes mostram-se incongruentes, ou seja, sugerem ações conjuntas que se contrapõem, tornando-se impraticáveis do ponto de vista sócio-ambiental e resultando tendenciosos em prol de finalidades lucrativas.

Tal desafio propõe a necessidade de conhecimento específico para a solução do essencial, com a eliminação gradativa dos entraves de caráter básico facilitando contribuir para soluções sustentáveis inclusive em uma perspectiva futura.

Embora o litoral do estado do Paraná apresente-se social e ambientalmente menos impactado do que em outras regiões costeiras do país, neste ainda se encontra uma grande incidência de problemas urbanos básicos destacando-se o aumento das ocupações irregulares. Pois segundo o plano diretor do município, em alguns balneários estas já atingem áreas com subtipos da Floresta Ombrófila Densa.

Quanto à atuação prejudicial do turismo no litoral de alguns estados, constatou-se que no Paraná a atividade não é a responsável pelos problemas sócioambientais como um todo, mas sim, a sua concentração e desequilíbrio.

Ressalta-se por esta razão, que no litoral paranaense determinados impactos causados pelo turismo ficam apenas restritos à concentração deste nas altas temporadas (dezembro, janeiro e fevereiro), exemplificado pelo caso do acúmulo de lixo e dejetos. Tal constatação, portanto, pode constituir um elemento-base para diagnósticos de prevenção de impactos que envolvam aspectos temporais.

Algumas regiões litorâneas do país já experimentaram condições de grande impacto, a sobrecarga do turismo sem planejamento resultou na saturação das condições ambientais (alto índice de poluição e lixo) acabando por inviabilizar a própria atividade (MENDONÇA, 2001).

Portanto, como atividade impactante, o turismo deve ser planejado sob a ótica ambiental, sobretudo em áreas litorâneas, consideradas naturalmente frágeis, visando tanto o conjunto das condições presentes quanto o seu caráter preventivo. 
O litoral do estado do Paraná em função de sua legislação apresenta um considerável grau de preservação ambiental, embora ainda existam conflitos decorrentes das formas de uso e ocupação do solo. Nesse aspecto, estudos de percepção ambiental também podem constituir ferramenta na obtenção de conhecimento e meios para solucionar impasses.

Como visto e para sua preservação, o município de Pontal do Paraná define em seu plano diretor os dispositivos legais buscando adequar o uso e a ocupação do solo incidindo de modo a conservar ainda um ambiente com impactos reduzidos.

$\mathrm{Na}$ conclusão do trabalho através da percepção ambiental dos moradores dos balneários pesquisados, podem-se ressaltar os principais impactos sócio-ambientais do turismo para estes locais:

a) Os moradores mostraram-se insatisfeitos com a administração pública quanto aos serviços essenciais - saneamento (esgotos) e destinação para o lixo, destacando-se ainda a precária limpeza e conservação deixada pela concentração do turismo nas altas temporadas de veraneio;

b) Os entrevistados, em geral, reivindicaram por parte da administração pública (estadual e municipal) melhorias para a exploração do turismo, pois de acordo com os mesmos a infra-instrutora deficiente desestimula qualquer iniciativa em outros investimentos relacionados à atividade.

c) Nos locais pesquisados, as transformações na paisagem ocorridas nas últimas décadas foram, sobretudo, em função dos crescimentos urbano e populacional associados ao turismo concentrado, provocando assim, o aumento dos impactos negativos ao meio ambiente (lixo e resíduos);

d) Segundo os moradores, os turistas ficam alienados em relação à sua conduta nos balneários comprometendo a limpeza e a conservação, pois vêem os locais apenas como espaço de lazer temporário. Sendo que os próprios moradores também são responsáveis pelo problema.

e) Os entrevistados afirmaram que nos balneários pesquisados - inclusive por observação de sua geografia comum - a satisfação dos turistas está totalmente atrelada à integridade do ambiente (natural e construído);

f) O público pesquisado, independentemente de gênero, faixa etária, grau de escolaridade e ocupação, não julgou o turismo prejudicial ao meio ambiente como um todo, mas sim, pela ausência de uma administração 
efetivamente ligada a este. Pois o turismo, considerado pelos moradores como impulsionador econômico encontra-se altamente concentrado e restrito às temporadas, constituindo apenas fonte de renda sazonal e trazendo impactos negativos de ordem ambiental e socioeconômica;

g) A insegurança vivida pelos moradores constitui o problema mais grave fora das temporadas de veraneio. Segundo estes, a exploração do turismo através de atividades fora de temporada possibilitaria maior movimentação local e suporte para a diminuição do problema;

h) As considerações dos entrevistados acerca da satisfatória conservação do meio ambiente nos balneários podem ser fundamentadas através da incidência da legislação de uso e ocupação do solo contida no plano diretor do município. Esta regulamenta os parâmetros de ocupação e inclusive as ZPAs - Zonas de Proteção Ambiental, estabelecidas e delimitadas com a finalidade de preservação das áreas naturais.

Porém, muitas destas evidências refletem um desconforto da população perante um panorama ainda deficiente do ponto de vista sócio-ambiental.

O resultado da pesquisa demonstrou uma reivindicação dos moradores dos balneários por investimentos e incentivos ao turismo fora das temporadas em prol de melhorias consideradas essenciais - limpeza, conservação, empregabilidade e principalmente segurança - que também agregaria melhor qualidade às infraestruturas e ao lazer das altas temporadas para moradores e turistas.

O estudo demonstrou que estes balneários em particular se caracterizam, em síntese, por uma situação de grande desequilíbrio - o turismo concentrado em época de veraneio proporciona fonte de renda temporária mas que pouco beneficia o todo, afeta o meio ambiente pela sobrecarga, e, em contrapartida, faz elevar a insegurança nas demais épocas do ano.

Assim, constatou-se que o melhor controle e distribuição do turismo propiciariam equilíbrio à situação descrita beneficiando os balneários sob vários aspectos.

A pesquisa proporcionou também, um diferencial para ajuste de condições que nem sempre pode ser identificado pelo poder público ao adotar e estabelecer políticas visando atender necessidades básicas e que ainda fomentem o desenvolvimento do turismo sustentável para o local. 
Portanto, a percepção ambiental torna-se um aporte a mais, podendo constituir um recurso empírico para diagnósticos sócio-ambientais possibilitando as bases para formulação de políticas públicas adequadas e com maior efeito.

Dessa forma, através da percepção do público pesquisado e junto à realidade observada foram também concluídas as possíveis sugestões de melhoria para o alcance das condições satisfatórias:

a) Implantação de melhores estruturas para suporte turístico nos balneários, como sinalização nas ruas, lixeiras e sanitários com devidas indicações;

b) Investimento em segurança conciliado a promover 0 interesse e a colaboração da comunidade.

c) Redimensionamento da atividade turística através de maiores incentivos e campanhas para a sua promoção fora das temporadas;

d) Melhoramento das infraestruturas urbanas básicas - saneamento, limpeza, conservação e destinação adequada para lixo e resíduos;

e) Educação ambiental com material didático que possa de forma funcional, conscientizar os próprios moradores e os turistas nas temporadas;

f) Observação da legislação de uso e ocupação do solo no município, para manutenção da preservação ambiental e promoção sustentável do turismo.

Concluiu-se que a exploração equilibrada e responsável do turismo pode trazer benefícios à região desde que vinculadas: às ações públicas - para melhoramento das condições locais (infraestruturas urbanas), ordenamento do território com critérios de exploração mediante as leis, fiscalização e educação ambiental; e à comunidade - pelo seu interesse e maior envolvimento no sentido de cooperar com todas as instituições.

A pesquisa sugeriu ainda que a realização efetiva de melhorias básicas locais, além de beneficiar o turismo facilitaria a melhor conciliação entre o crescimento econômico, o bem estar social e a preservação do meio ambiente.

Por fim, através do estudo, constatou-se que por meio de ações locais e que possam refletir em uma escala global configuram-se as condições essenciais para integrar políticas públicas satisfatórias buscando o desenvolvimento sustentável e seus benefícios, tornando-os realmente possíveis e ao alcance de todos. 


\section{REFERÊNCIAS}

AMORIM FILHO, O. B. O contexto teórico do desenvolvimento dos estudos humanísticos e perceptivos na Geografia. Belo Horizonte: Publicação especial, 1987. $42 \mathrm{p}$.

. Os estudos de percepção como a última fronteira da gestão ambiental. ICG/Universidade Federal de Minas Gerais. Artigo. Disponível em: <http://www.uol.com.br/ivairr/percepcaoambi.htm> Acesso em: 12 mar. 2006.

AMORIM FILHO, O. B.; ABREU, J. F. Imagem, representação e geopolítica. In: MENDONÇA, F.: KOZEL, S. (orgs). Elementos de epistemologia da geografia contemporânea. Curitiba: UFPR, 2002, p. $233-251$.

ANDRADE, J. V. Turismo: fundamentos e dimensões. 8. ed. São Paulo: Ática, 2002.

ANGULO, R. J. Geologia da planície costeira do Estado do Paraná. São Paulo, 1992. Tese (Doutorado em Geociências) Instituto de Geociências da Universidade de São Paulo.

ANGULO, R. J.; SOUZA, M. C. Morfologia Costeira. In: LIMA, R. E.; NEGRELLE, R. R. B. (orgs.). Meio ambiente e desenvolvimento no litoral do Paraná: diagnóstico. Curitiba: UFPR; Brasília: CNPq, 1998, p. 175 - 184.

BIGARELLA, J. J. Contribuição ao estudo da planície litorânea do Estado do Paraná. Arq. Biol. Tecn., Curitiba, v. 1, 1946.

A Serra do Mar e a porção oriental do Estado do Paraná. Governo do Paraná. Secretaria do Estado do Planejamento / ADEA, 1978.

COLIT - Conselho de Desenvolvimento Territorial do Litoral Paranaense. Mapa Zoneamento Decreto Estadual 2722/84. Acervo técnico, 2002/ 2003/ 2004.

CRUZ, C.; RIBEIRO, U. Metodologia científica: teoria e prática. 2. ed. Rio de Janeiro: Axcel Books, 2004.

DIMUTUR - Diretoria Municipal de Turismo. Plano Diretor Municipal (documento das secretarias). Prefeitura Municipal de Pontal do Paraná. 2006.

GADE, C. Psicologia do consumidor. São Paulo: Editora Pedagógica e Universitária, 1980.

GOVERNO DO PARANÁ E PREFEITURA MUNICIPAL DE PONTAL DO PARANÁ. Plano Diretor de Desenvolvimento Integrado - Matinhos/Pontal do Paraná. 1 CD - ROM, 2004.

IPARDES - Instituto Paranaense de Desenvolvimento Econômico e Social. Anuário estatístico do estado do Paraná 2005. Disponível em: <http://www.ipardes.gov.br/anuario 2005/index.html> Acesso em: 22 out. 2006. 
LIMA, R. E.; NEGRELLE, R. R. B. (orgs.). Meio ambiente e desenvolvimento no litoral do Paraná: diagnóstico. Curitiba: UFPR; Brasília: CNPq, 1998.

MAACK, R. Geografia física do estado do Paraná. 2. ed. Rio de Janeiro: José Olympio Editora, 1981.

MELLO, J. B. F. Geografia humanística: a perspectiva da experiência vivida e uma crítica radical ao positivismo. Revista Brasileira Geográfica, Rio de Janeiro, 52 (4), p. 91 - 115, out./dez., 1990.

MENDONÇA, R. Turismo ou meio ambiente: uma falsa oposição? In: LEMOS, A. I. G. (org.). Turismo: impactos sócio-ambientais. 3. ed. São Paulo: Hucitec, 2001. p. $19-25$.

MINISTÉRIO DO MEIO AMBIENTE. Agenda 21. Brasília, DF. Disponível em: <http://www.mma.gov.br> Acesso em: 14 abr. 2007.

MORAES, A. C. R. Geografia: pequena história crítica. 19. ed. São Paulo: Annablume, 2003.

OLIVEIRA, L. Percepção e representação do espaço geográfico. In: DEL RIO, V.; OLIVEIRA, L. Percepção ambiental: a experiência brasileira. São Paulo: Studio Nobel, Universidade Federal de São Carlos, 1996, p. 187 - 212.

. Percepção da paisagem geográfica: Piaget, Gibson e Tuan. Geografia. Rio Claro, v. 25, n. 2, 2000, p. $05-22$.

Ainda sobre percepção, cognição e representação em geografia. In: MENDONÇA, F.: KOZEL, S. (orgs). Elementos de epistemologia da geografia contemporânea. Curitiba: UFPR, 2002, p. 189 - 196.

OMT - Turismo Sustentável. In: Introdução ao turismo. São Paulo: Roca, 2001. p. $243-260$.

RAUPP, M.; REICHLE, A. Avaliação: ferramenta para melhores projetos. Santa Cruz do Sul: EDINISC, 2003.

RODRIGUES, A. B. Turismo e espaço: rumo a um conhecimento transdisciplinar. São Paulo: Hucitec, 2001.

SACHS, I. Estratégias de transição para o século XXI: desenvolvimento e meio ambiente. São Paulo: Vértice, 1993.

SILVEIRA, M. A. T. da. Planejamento territorial e dinâmica local: bases para o turismo sustentável. In: RODRIGUES, A. B. (org.). Turismo e desenvolvimento local. 1. ed. São Paulo: Hucitec, 1997, p. 87 - 98.

Para pensar o território a partir do turismo. Trabalho apresentado no $\mathrm{V}$ ANPEGE, USP. São Paulo: USP, 2001. 14 p. 
. Turismo, políticas de ordenamento territorial e desenvolvimento: um foco no estado do Paraná no contexto regional. São Paulo, 2002. Tese (Doutorado) FFLCH, Universidade de São Paulo.

TUAN, Y. F. Topofilia: um estudo da percepção, atitudes e valores do meio ambiente. Tradução: Lívia de Oliveira. São Paulo: Difel, 1980.

(Recebido em 07.04.2011. Aceito em 03.11.2011) 